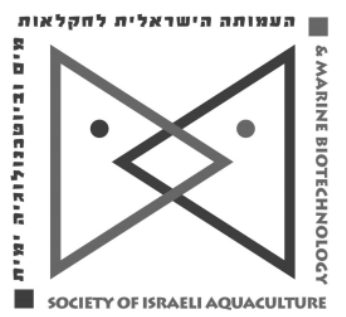

The IJA appears exclusively as a peer-reviewed on-line open-access journal at http://www.siamb.org.il. To read papers free of charge, please register online at registration form.

Sale of IJA papers is strictly forbidden.

\title{
Response of Hatchery-Cultured Mud Crab (Scylla paramamosain) Instar Fed Natural Prey and an Artificial Feed
}

\author{
Yang-yang Gong ${ }^{1}$, Jian-xue $\mathrm{Lu}^{1}$, Xiao-shan Wang, Yan-qing Huang*
}

Key Laboratory of East China Sea \& Oceanic Fishery Resources Exploitation and Utilization, Ministry of Agriculture, East China Sea Fisheries Research Institute, Chinese Academy of Fishery Sciences, Shanghai 200090, China

Keywords: mud crab; artificial feed; growth; amino acid; coloration

\begin{abstract}
A 60 day feeding trial was carried out to evaluate the effect on growth, survival, amino acid composition, and coloration of hatchery-cultured mud crab (Scylla paramamosain) instar $(0.41 \pm 0.05 \mathrm{~g})$ fed: fish Harpadon nehereus, Chinese mystery snail Cipangopaludina chinensis, and artificial feed. Each food type was assigned to eight tanks (10 crabs per tank). Results showed that the growth of mud crab is significantly affected by food type. Crabs fed the artificial feed showed specific growth rate comparable to crabs fed the snail $C$. chinensis, and higher growth rate compared to crabs consuming fish $H$. nehereus. Amino acid profiles of whole crabs were found to be highly correlated with dietary amino acid profiles. Crabs fed dry feed showed higher L* value (lighter colour) and $b^{*}$ value (higher intensity in blue colour) compared to crabs fed the other two diets. In conclusion, it is clear that artificial feed is potentially an alternative diet for hatchery-cultured mud crab (S. paramamosain) instar in terms of growth rate. However, it is suggested that paler carapace color might be related to insufficient dietary intake of carotenoids from the artificial feed.
\end{abstract}

\footnotetext{
${ }^{*}$ Corresponding author. E-mail address: yanggo@126.com

${ }^{1}$ These authors contributed equally to this work
} 


\section{Introduction}

The mud crab of the genus Scylla is distributed throughout a vast geographic area, ranging from coasts of southeast Africa to Indo-Pacific regions (Fuseya and Watanabe 1996). Scylla paramamosain, one of the species of the genus Scylla, mainly inhabits the coasts of China, Vietnam, and Japan (Takano et al., 2005). They are valuable to commercial fisheries in many countries and have many favorable features for aquaculture. Mud crabs are omnivorous scavengers with diets including a wide range of animal and plant materials, including mollusks, small crustaceans, polychaetes, and detritus (Hill 1976). They have a high specific growth rate (SGR) that varies between 3\% and 10\% (Triño et al., 1999; Unnikrishnan and Paulraj 2010). Under captive conditions, juvenile mud crabs can grow to market size (200-300 g) within 4-6 months (Triño and Rodriguez 2002). In addition, mud crabs are highly valued for their large size, muscle flavor, and high meat yield. The huge market demand and high price has led to the growth in both the fishery and aquaculture sectors in these countries. Mud crab $S$. paramamosain has become one of the most important crustaceans in Chinese aquaculture. In recent years, the total culture yields of $S$. paramamosain have remained stable at approximately 110,000 tons per year (Ma et al., 2014). However, current culture capacity cannot meet market demand.

Farming of S. paramamosain depends mainly on conventional natural fresh food such as trash fish and mollusks. This dependence on natural food is a constraint that inhibits the development of mud crab farming on a larger commercial scale. To overcome this problem it is essential to use cost-effective and nutritionally adequate artificial feed. Natural food items have a seasonal variation in quality and nutritional value and can result in wastage and environmental degradation. For the past few years there have been an increasing number of research efforts to evaluate the specific nutritional requirements of mud crabs Scylla spp. A diet containing $5.3 \%-13.8 \%$ lipid with $48 \%$ protein met the dietary needs of Scylla serrata megalopa (Sheen and Wu (1999). Good growth was obtained when juvenile mud crabs Scylla serrata $(9 \mathrm{~g})$ were fed a diet containing $32-40 \%$ dietary protein with either $6 \%$ or $12 \%$ lipid (Catacutan (2002). It was found that a proper dietary lipid level of $8.52 \%-11.63 \%$ (optimum $9.5 \%$ ) could maintain solid growth performance and antioxidant capacity of juvenile mud crab S. paramamosain (11 g) (Zhao et al., (2015). However, the development of a suitable formulated optimal artificial feed for $S$. paramamosain juveniles growth is limited and information is scarce regarding growth, coloration, its preferences for natural feed vs. artificial diets. The current study aimed to investigate the effects of feeding hatchery-cultured mud crab S. paramamosain instar with three different food types. The effects were assessed by measuring the survival, growth, whole body amino acid composition, and coloration.

\section{Materials and Methods}

Broodstock and larval rearing. Impregnated female mud crabs S. paramamosain (around 300 g) were captured and transported to the research station. The selected crabs were then placed in $20 \mathrm{~m}^{3}\left(20 \mathrm{~m}^{2} \times 1 \mathrm{~m}\right)$ cement tanks, with a sand layer of $15 \mathrm{~cm}$ covering $70 \%$ of the tank bottom at a density of one $\mathrm{crab} / \mathrm{m}^{2}$ for a period of about three weeks before hatching began. The mud crabs were fed live bivalves such as Sinonovacula constricta and Meretrix meretrix once a day, ad libitum. The tanks were continuously supplied with seawater at $25-28^{\circ} \mathrm{C}$ and salinity at $25 \mathrm{~g} / \mathrm{L}$.

Two days before hatching the broodstock were transferred to $1 \mathrm{~m}^{3}$ hatching tanks. The larvae from all females hatched on the same day were mixed together and raised in $32.5 \mathrm{~m}^{3}$ ( 25 $\mathrm{m}^{2} \times 1.3 \mathrm{~m}$ ) cement tanks at a density of $10000 / \mathrm{m}^{3}$ and were fed daily with rotifer enriched with 50DE (Shengsuo Technologies, Yantai, China) (Zoeae I to III), later Artemia nauplii enriched with 50DE (Shengsuo Technologies, Yantai, China) (Zoeae III to V) and Artemia juvenile (Megalopa) until the first stage juvenile instar (C1). The juvenile instars were fed chopped bivalves until they were collected for the feeding experiment.

Experimental design. The feeding experiment was carried out in a flow-through system at the research station. The system consisted of 24 individual rearing tanks with $40 \mathrm{~L}$ seawater per tank. Disinfected roll tiles were placed as shelters. Third stage juvenile instars (C3) with a mean initial weight and initial carapace width of $0.41 \pm 0.05 \mathrm{~g}$ and $1.29 \pm 0.01 \mathrm{~cm}$ respectively, were collected randomly from the larval rearing tanks shortly after they settled, and were placed in 8 replicate tanks. The rearing water temperature ranged from $26-28^{\circ} \mathrm{C}$, salinity was $25 \mathrm{~g} / \mathrm{L}$. 
Three different diets were fed during the experimental period of 60 days. The three diets were: 1) trash fish Harpadon nehereus; 2) Chinese mystery snail Cipangopaludina chinensis; and 3) an artificial feed. (see Table 1)

Table 1. Chemical/nutritional composition of three experimental diets

\begin{tabular}{lccc}
\hline & Fish (H. nehereus) & Snail (C. chinensis) & Artificial feed \\
\hline Moisture & 85.37 & 77.98 & 9.17 \\
$\begin{array}{l}\text { Dry matter basis } \\
(g / 100 g \text { DM) }\end{array}$ & & & \\
Protein & 68.56 & 64.49 & 55.86 \\
Lipid & 16.61 & 3.22 & 17.33 \\
Ash & 10.46 & 20.21 & 13.05 \\
Threonine & 3.11 & 2.90 & 1.94 \\
Valine & 3.61 & 3.02 & 2.38 \\
Leucine & 5.71 & 4.95 & 3.67 \\
Isoleucine & 3.11 & 2.76 & 2.04 \\
Methionine & 1.31 & 0.93 & 0.57 \\
Phenylalanine & 2.66 & 2.46 & 2.07 \\
Lysine & 6.16 & 4.68 & 3.33 \\
Tryptophan & 0.46 & 0.47 & 0.36 \\
Arginine & 4.57 & 4.38 & 2.82 \\
Histidine & 1.64 & 1.56 & 1.10 \\
Tyrosine & 2.42 & 2.41 & 1.46 \\
Glutamine & 11.00 & 8.98 & 7.94 \\
Asparagine & 6.63 & 6.08 & 4.44 \\
Alanine & 4.57 & 3.46 & 2.90 \\
Glycine & 4.07 & 2.80 & 2.80 \\
Proline & 3.36 & 2.86 & 2.58 \\
Serine & 2.74 & 3.47 & 1.96 \\
\hline
\end{tabular}

$H$. nehereus and $C$. chinensis are commonly used as primary food for commercial mud crab culture. The artificial feed consisted of fish meal, soybean meal, wheat bran, wheat meal, fish oil, soy oil, soy lecithin, cholesterol, commercial binder, monobasic calcium phosphate, vitamin and mineral premix. All feed ingredients were of commercial quality and were supplied by Shanghai Sanzhi-bio Co. Ltd. The artificial feed was prepared at the feed lab. The diets were prepared by thoroughly mixing all the ingredients in a kitchen mixer. The homogeneous mixture was blended with water to obtain malleable dough which was cold-pressed through a meat mincer with a $2 \mathrm{~mm}$ die to produce spaghetti-like strings, which were then cut into small pellets. The pellets $\left(2-3 \mathrm{~mm}\right.$ length) were then dried in an oven at $35^{\circ} \mathrm{C}$ and vacuum packed and stored at $4^{\circ} \mathrm{C}$ until use. Crabs were fed three meals per day at 07:00, 12:00 and 19:00 hours. All diets were administered to satiation level ( $4-8 \%$ body weight). Uneaten food and fecal waste were removed daily by siphoning.

Survival was calculated by counting all the crabs in each tank at day 1 , and day 60 . Individual weight and carapace width was recorded at the start and end of the experiment from each tank. Growth, crab weight gain, specific growth rate, and carapace width increment were determined.

Three crabs per tank were randomly selected for carapace color measurement and whole body amino acid composition analysis. A colorimeter (Konica Minolta CR-400, Osaka, Japan) was used to measure the crab's carapace color parameters in the CIELAB color space (CIE 1976). $L^{*}$ represents lightness ( $L^{*}=0$ for black, and $L^{*}=100$ for white), a* describes intensity in green $\left(a^{*}<0\right)$ or red $\left(a^{*}>0\right)$, and $b^{*}$ represents intensity in blue $\left(b^{*}<0\right)$ or yellow (b* $>$ $0)$. Three readings were taken from the center of the carapace and the average value was calculated for each group. The amino acid content of diets and whole crab samples were analyzed using the methods outlined by Tang et al., (2016). The samples were then ground, homogenized, and freeze-dried for further analysis, and were hydrolyzed with $6 \mathrm{~mol} / \mathrm{L} \mathrm{HCl}$ for $24 \mathrm{~h}$ at $110^{\circ} \mathrm{C}$. The hydrolysate was dried under vacuum, dissolved in sodium citrate solution $(\mathrm{pH} 2.2)$ and filtered through a $0.45-\mu \mathrm{m}$ Millipore nylon membrane filter. Amino acid analysis was performed using $1 \mu \mathrm{L}$ of sample with a Biochrom 20 Amino Acids Analyzer (Biochrom Ltd., Cambridge, UK). The amino acid composition of the samples were calculated by comparison with the retention time and peak areas of the standards (Sigma-Aldrich, St. Louis, MO, USA). Amino acid concentration was presented as $\mathrm{g} / 100 \mathrm{~g}$ dry weight. Pearson Correlation coefficient 
was employed between dietary and whole crab amino acid compositions according to Mente (2010).

Calculations and statistical analyses. Crab growth performance was calculated with the following equations:

Survival rate $(\%)=100 \times$ Final number/ Initial number

Specific growth rate $(\mathrm{SGR}, \%)=100 \times[(\mathrm{Ln}(\mathrm{FW})-\mathrm{Ln}(\mathrm{IW})] /$ days fed

Carapace width increment $(\mathrm{cm})=$ Final carapace width $(\mathrm{cm})$ - Initial carapace width $(\mathrm{cm})$.

All statistical analyses were performed using SPSS 21.0 software package for Windows. The data were tested for normality (Shapiro-Wilk normality test) and Levene's test of equality. Significant differences among values were determined by the Tukey's HSD test. The differences were regarded as significant when $\mathrm{P}<0.05$.

\section{Results}

Survival. The average survival rate across all dietary treatments was $48.1 \%$ (Table 2 ). There was no statistical difference in the survival rate among the three dietary treatments.

Table 2. Effects of different diets on the survival rate and growth of Scylla paramamosain

\begin{tabular}{|c|c|c|c|}
\hline & Fish (H. nehereus) & Snail (C. chinensis) & Artificial feed \\
\hline Survival rate $(\%)^{1}$ & $45.8 \pm 3.25^{\mathrm{a}}$ & $49.7 \pm 4.57^{\mathrm{a}}$ & $48.7 \pm 3.19^{\mathrm{a}}$ \\
\hline Final weight $(\mathrm{g})$ & $3.69 \pm 1.52^{\mathrm{c}}$ & $13.00 \pm 4.25^{\mathrm{a}}$ & $8.92 \pm 1.03^{b}$ \\
\hline $\operatorname{SGR}(\%)^{2}$ & $3.77 \pm 0.82^{b}$ & $6.08 \pm 0.61^{a}$ & $5.49 \pm 0.21^{\mathrm{a}}$ \\
\hline Carapace width increment $(\mathrm{cm})^{3}$ & $1.42 \pm 0.39^{\mathrm{b}}$ & $2.67 \pm 0.69^{a}$ & $2.10 \pm 0.17^{a}$ \\
\hline
\end{tabular}

Values in the same row with different superscripts are significantly different $(P<0.05)$.

${ }^{1}$ Survival rate $=100 \times$ Final crab number/ Initial crab number

${ }^{2}$ Specific growth rate $(\mathrm{SGR})=100 \times[(\mathrm{Ln}(\mathrm{FBW}, \mathrm{g})-\mathrm{Ln}(\mathrm{IBW}, \mathrm{g})] /$ day fed

${ }^{3}$ Carapace width increment $=$ Final carapace width $(\mathrm{cm})-$ Initial carapace width $(\mathrm{cm})$

Growth. The growth performance of mud crab fed with different diets was compared in terms of final weight, SGR and carapace width increment (Table 2). Initially, the crabs had an average carapace width of $1.29 \pm 0.01 \mathrm{~cm}$ and average wet weight of $0.41 \pm 0.05 \mathrm{~g}$. After the feeding experiment, crabs molted and their carapace width reached an average of $3.36 \pm 0.63$ $\mathrm{cm}$ and an average final weight of $8.53 \pm 4.67 \mathrm{~g}$. Mud crabs fed on snails $C$. chinensis reached highest final weight but with large variations compared to crabs fed trash fish and artificial feed $(P<0.05)$. Crabs fed on snails $C$. chinensis, and artificial feed had a significantly higher SGR and carapace width increment as compared with crabs that were fed trash fish $H$. nehereus ( $P$ $<0.05)$. There were no differences in SGR and carapace width increment between crabs fed $C$. chinensis and the ones fed artificial feed.

Amino acid composition. Amino acid contents of whole crab samples from three dietary groups are shown in Table 3.

Table 3. Effects of different diets on the amino acid composition of whole Scylla paramamosain ( $100 \mathrm{~g} / \mathrm{dry}$ weight)

\begin{tabular}{llll}
\hline & Fish (H. nehereus) & Snail (C. chinensis) & Artificial feed \\
\hline Threonine & $1.65 \pm 0.08^{\mathrm{ab}}$ & $1.73 \pm 0.03^{\mathrm{a}}$ & $1.47 \pm 0.17^{\mathrm{b}}$ \\
Valine & $1.98 \pm 0.06^{\mathrm{a}}$ & $1.81 \pm 0.06^{\mathrm{ab}}$ & $1.73 \pm 0.16^{\mathrm{b}}$ \\
Leucine & $2.60 \pm 0.02^{\mathrm{a}}$ & $2.49 \pm 0.04^{\mathrm{ab}}$ & $2.34 \pm 0.21^{\mathrm{b}}$ \\
Isoleucine & $1.49 \pm 0.02^{\mathrm{a}}$ & $1.44 \pm 0.01^{\mathrm{ab}}$ & $1.33 \pm 0.12^{\mathrm{b}}$ \\
Methionine & $0.55 \pm 0.02^{\mathrm{a}}$ & $0.12 \pm 0.03^{\mathrm{b}}$ & $0.26 \pm 0.21^{\mathrm{b}}$ \\
Phenylalanine & $1.62 \pm 0.03^{\mathrm{a}}$ & $1.52 \pm 0.02^{\mathrm{a}}$ & $1.50 \pm 0.20^{\mathrm{a}}$ \\
Lysine & $2.68 \pm 0.02^{\mathrm{a}}$ & $2.60 \pm 0.02^{\mathrm{a}}$ & $2.49 \pm 0.31^{\mathrm{a}}$ \\
Tryptophan & $0.30 \pm 0.01^{\mathrm{ab}}$ & $0.27 \pm 0.06^{\mathrm{b}}$ & $0.37 \pm 0.04^{\mathrm{a}}$ \\
Arginine & $2.84 \pm 0.08^{\mathrm{a}}$ & $2.83 \pm 0.02^{\mathrm{a}}$ & $2.71 \pm 0.31^{\mathrm{a}}$ \\
Histidine & $1.04 \pm 0.04^{\mathrm{a}}$ & $1.02 \pm 0.01^{\mathrm{a}}$ & $1.03 \pm 0.12^{\mathrm{a}}$ \\
Tyrosine & $1.61 \pm 0.06^{\mathrm{a}}$ & $1.46 \pm 0.08^{\mathrm{ab}}$ & $1.35 \pm 0.17^{\mathrm{b}}$ \\
Glutamine & $5.62 \pm 0.14^{\mathrm{a}}$ & $5.36 \pm 0.24^{\mathrm{a}}$ & $4.88 \pm 0.70^{\mathrm{a}}$ \\
Asparagine & $3.76 \pm 0.04^{\mathrm{a}}$ & $3.48 \pm 0.04^{\mathrm{ab}}$ & $3.33 \pm 0.34^{\mathrm{b}}$ \\
Alanine & $2.31 \pm 0.18^{\mathrm{a}}$ & $2.07 \pm 0.06^{\mathrm{a}}$ & $1.94 \pm 0.27^{\mathrm{a}}$ \\
Glycine & $3.00 \pm 0.17^{\mathrm{a}}$ & $2.86 \pm 0.32^{\mathrm{a}}$ & $3.06 \pm 0.04^{\mathrm{a}}$ \\
Proline & $2.09 \pm 0.02^{\mathrm{ab}}$ & $2.30 \pm 0.04^{\mathrm{a}}$ & $1.80 \pm 0.25^{\mathrm{b}}$ \\
Serine & $1.56 \pm 0.06^{\mathrm{a}}$ & $1.51 \pm 0.02^{\mathrm{a}}$ & $1.38 \pm 0.18^{\mathrm{a}}$
\end{tabular}

Values in the same row with different superscripts are significantly different $(P<0.05)$. 
In the mud crab studied, lysine, arginine, and leucine represented nearly $50 \%$ of total essential amino acids, and glutamate and asparagine represented half of total non-essential amino acids as well. Some significant differences were observed in individual amino acids between groups; the level of valine, leucine, isoleucine, methionine, tyrosine, asparagine was higher in crabs fed with fish $H$. nehereus compared with crabs fed with artificial feed $(P<0.05)$. Threonine and proline levels were higher in crabs fed with $C$. chinensis than crabs fed with artificial feed $(P<$ 0.05). Among the amino acids, tryptophan was accumulated in higher amounts in crabs fed with artificial feed than with crabs fed with $C$. chinensis. The amino acid profiles of whole crabs fed with the $H$. nehereus $\left(R^{2}=0.9342\right)$ were highly correlated with the dietary amino acid profiles of $H$. nehereus. The amino acid composition of the whole crab exhibited similar correlation between $C$. chinensis $\left(R^{2}=0.8919\right)$ and artificial feed $\left(R^{2}=0.8996\right)$.

Coloration. Measured instrumentally, lightness ( $\left.L^{*}\right)$ was higher in the crabs fed artificial dry feed compared to the other two groups $(P<0.05)$ (Table 4$)$. The instrumental color analysis revealed that crabs fed snails had highest $b^{*}$ value of the three treatments while crabs fed artificial feed had the lowest $b^{*}$ value $(\mathrm{P}<0.05)$. There was no significant difference in $a^{*}$ value among the dietary treatments.

Table 4. Effects of different diets on the central carapace color of Scylla paramamosain

\begin{tabular}{lccc}
\hline & Fish $($ H. nehereus) & Snail (C. chinensis) & Artificial feed \\
\hline$L^{*}$ & $35.68 \pm 3.67^{\mathrm{b}}$ & $33.33 \pm 1.28^{\mathrm{b}}$ & $45.47 \pm 4.44^{\mathrm{a}}$ \\
$a^{*}$ & $-0.98 \pm 0.45^{\mathrm{a}}$ & $-0.60 \pm 0.22^{\mathrm{a}}$ & $-1.47 \pm 0.55^{\mathrm{a}}$ \\
$b^{*}$ & $-4.09 \pm 1.12^{\mathrm{b}}$ & $2.88 \pm 0.95^{\mathrm{a}}$ & $-9.59 \pm 1.53^{\mathrm{c}}$ \\
\hline
\end{tabular}

Values in the same row with different superscripts are significantly different $\quad(P<0.05)$.

\section{Discussion}

The primary aim of the present study was to compare three different diets on survival rate, growth, amino acid composition, and coloration of hatchery-cultured mud crab $S$. paramamosain. Mud crabs are active predators and have a wide feeding spectrum, including crustaceans, molluscs, fish, and even detritus (Hill 1976). In the present study, snail $C$. chinensis and fish $\mathrm{H}$. nehereus were chosen as diets for mud crab due to their abundant use in commercial mud crab farming in China. These natural diets were compared to an artificial diet. This study has shown that as well as natural diets, artificial feed can be well accepted by mud crab.

The juvenile crabs showed no significant difference in survival rate across the three dietary treatments. Growth of crabs is commonly expressed in SGR and carapace width increment (Holme et al., 2009). The artificial feed used in this study showed SGR and carapace width increment comparable to that of a diet of snails ( $C$. chinensis), and even better than that observed when crabs were fed on trash fish ( $H$. nehereus). The three diets differed in nutritional composition. Chemical analyses revealed that artificial feed had $56 \%$ protein and $17 \%$ lipid; whereas $C$. chinensis had $65 \%$ protein and only $3 \%$ lipid and $H$. nehereus had $68 \%$ protein and $16 \%$ lipid. In this study, the protein and lipid levels in C. chinensis seemed optimal for mud crab instars. In the literature, optimal levels vary widely among different species at different developmental stages and environments. For most juvenile crustaceans, good growth can be obtained with total protein levels between $30 \%$ and $60 \%$ of diet (dry weight), and lipid level from $2 \%-17 \%$ of diet (dry weight) (Holme et al., 2009). A diet containing $50 \%$ protein and $5 \%-14 \%$ lipid was found to be sufficient for $12 \mathrm{~g}$ mud crab, Scylla serrata, (Sheen and Wu, 1999). An optimal protein level of $32-40 \%$ and lipid level of $6-12 \%$ for $9 \mathrm{~g}$ mud crab Scylla serrate was reported (Catacutan, 2002). However, the lipid level in artificial feed and trash feed seems to be too high for mud crab instars. Excessive dietary lipids are commonly known to have adverse effects on the growth and survival of crustaceans (Karapanagiotidis et al., 2015).

The efficiency of diets for cultured animals is also influenced by the digestibility and amino acid composition of the diets (Villanueva et al., 2004; Glencross et al., 2007). The main protein sources included in the artificial feed were fishmeal and soybean meal. These feedstuffs were highly digestible to mud crab as reported in earlier studies (Catacutan et al., 2003). There were some differences between the three diets with respect to their amino acid concentrations, and there was a high level of correlation between dietary amino acids and amino acid composition 
of whole mud crabs fed the respective diet $\left(R^{2}=0.9\right)$. In spite of higher levels of most amino acids in $H$. nehereus than $C$. chinensis, there were no differences in amino acid composition of crabs fed these two diets except for methionine. Although there were lower levels of most amino acids in artificial feed compared to C. chinensis (e.g. lysine, arginine, glutamine, asparagine, threonine, proline and serine), the ones found in the composition of whole crabs are practically the same except for proline and threonine. It is thus speculated that the amino acid profile of artificial feed is generally well balanced and can fulfill the growth of mud crab instars. Deviations from artificial feed for threonine and proline may suggest a deficiency of these amino acids in this diet, but further investigation is needed. Considering the better growth performance of mud crabs fed $C$. chinensis, the essential amino acid pattern of whole body $C$. chinensis can be considered to be representative of the essential amino acid requirements and provide guidelines for future mud crab artificial feed formulation (Kaushik 1998; Mente et al., 2002).

Crabs fed artificial feed showed higher $L^{*}$ value (lighter color) and $b^{*}$ value (higher intensity of blue color) compared to crabs fed the other two diets. Crabs fed snail $C$. chinensis were observed to have darker and higher intensity green and yellow color, which is a desired coloration in wild crabs. The $\beta$-carotene, lutein, zeaxanthin, fucoxanthin and canthaxanthin were reported to be the major carotenoids found in the snail C. chinensis (Maoka et al., 2012). Further assessment of dietary carotenoid levels is necessary for mud crab S. paramamosain instars.

Based on this study, artificial feed appears to be a positive alternative diet for mud crab Scylla paramamosain at early stages. However, it seems that artificial feed containing high amounts of lipid is not optimal for advanced instars of mud crab and sources containing carotenoids such as astaxanthin also need to be incorporated to obtain better coloration.

\section{Acknowledgements}

This work was supported by Fund Program for the Scientific Activities of Selected Returned Overseas Professionals in Shanghai and Central Non-profit Basic Scientific Research Project for the Scientific Research Institutes of China [No.East-2014Z01-4].

\section{References}

Catacutan M. R., 2002. Growth and body composition of juvenile mud crab, Scylla serrata, fed different dietary protein and lipid levels and protein to energy ratios. Aquaculture, 208(1): 113-123.

Catacutan M. R., P. S. Eusebio and S.-i. Teshima, 2003. Apparent digestibility of selected feedstuffs by mud crab, Scylla serrata. Aquaculture, 216(1): 253-261.

Fuseya R. and S. Watanabe, 1996. Genetic Varability in the Mud Crab Genus Scylla (Brachyura: Portunidae). Fish. Sci., 62(5): 705-709.

Glencross B., M. Booth and G. Allan, 2007. A feed is only as good as its ingredients-a review of ingredient evaluation strategies for aquaculture feeds. Aquacult. Nutr., 13(1): 17-34.

Hill B., 1976. Natural food, foregut clearance-rate and activity of the crab Scylla serrata. Mar. Biol., 34(2): 109-116.

Holme M.-H., C. Zeng and P. C. Southgate, 2009. A review of recent progress toward development of a formulated microbound diet for mud crab, Scylla serrata, larvae and their nutritional requirements. Aquaculture, 286(3): 164-175.

Karapanagiotidis I. T., E. Mente, P. Berillis and G. Rotllant, 2015. Measurement of the feed consumption of Nephrops norvegicus feeding on different diets and its effect on body nutrient composition and digestive gland histology. J. Crust. Biol., 35(1): 11-19.

Kaushik S. J., 1998. Whole body amino acid composition of European seabass (Dicentrarchus labrax), gilthead seabream (Sparus aurata) and turbot (Psetta maxima) with an estimation of their IAA requirement profiles. Aquat. Living Resour., 11(5): 355-358.

Ma H., W. Jiang, P. Liu, N. Feng, Q. Ma, C. Ma, S. Li, Y. Liu, Z. Qiao and L. Ma, 2014. Identification of transcriptome-derived microsatellite markers and their association with the growth performance of the Mud Crab (Scylla paramamosain). PloS one, 9(2): e89134.

Maoka T., J. Ochi, M. Mori and Y. Sakagami, 2012. Identification of Carotenoids in the Freshwater Shellfish Unio douglasiae nipponensis, Anodonta lauta, Cipangopaludina chinensis laeta, and Semisulcospira libertina. Journal of oleo science, 61(2): 69-74.

Mente E., 2010. Survival, food consumption and growth of Norway lobster (Nephrops norvegicus) kept in laboratory conditions. Integrative zoology, 5(3): 256-263. 
Mente E., P. Coutteau, D. Houlihan, I. Davidson and P. Sorgeloos, 2002. Protein turnover, amino acid profile and amino acid flux in juvenile shrimp Litopenaeus vannamei: effects of dietary protein source. J. Exp. Biol., 205(20): 3107-3122.

Sheen S.-S. and S.-W. Wu, 1999. The effects of dietary lipid levels on the growth response of juvenile mud crab Scylla serrata. Aquaculture, 175(1): 143-153.

Takano M., A. Barinova, T. Sugaya, Y. Obata, T. Watanabe, M. Ikeda and N. Taniguchi, 2005. Isolation and characterization of microsatellite DNA markers from mangrove crab, Scylla paramamosain. Mol. Ecol. Notes, 5(4): 794-795.

Tang B., W. Wei, Y. Huang, X. Zou and Y. Yue, 2016. Growth performance and nutritional composition of Hemifusus ternatanus under artificial culturing conditions. Aquaculture, 459: 186-190.

Triño A. T., O. M. Millamena and C. Keenan, 1999. Commercial evaluation of monosex pond culture of the mud crab Scylla species at three stocking densities in the Philippines. Aquaculture, 174(1): 109-118.

Triño A. T. and E. M. Rodriguez, 2002. Pen culture of mud crab Scylla serrata in tidal flats reforested with mangrove trees. Aquaculture, 211(1): 125-134.

Unnikrishnan U. and R. Paulraj, 2010. Dietary protein requirement of giant mud crab Scylla serrata juveniles fed iso-energetic formulated diets having graded protein levels. Aquacult. Res., 41(2): 278-294.

Villanueva R., J. Riba, C. Rulz-Capillas, A. González and M. Baeta, 2004. Amino acid composition of early stages of cephalopods and effect of amino acid dietary treatments on Octopus vulgaris paralarvae. Aquaculture, 242(1): 455-478.

Zhao J., X. Wen, S. Li, D. Zhu and Y. Li, 2015. Effects of dietary lipid levels on growth, feed utilization, body composition and antioxidants of juvenile mud crab Scylla paramamosain (Estampador). Aquaculture, 435: 200-206. 